\title{
Vitamin D status, hypertension and body mass index in an urban black community in Mangaung, South Africa
}

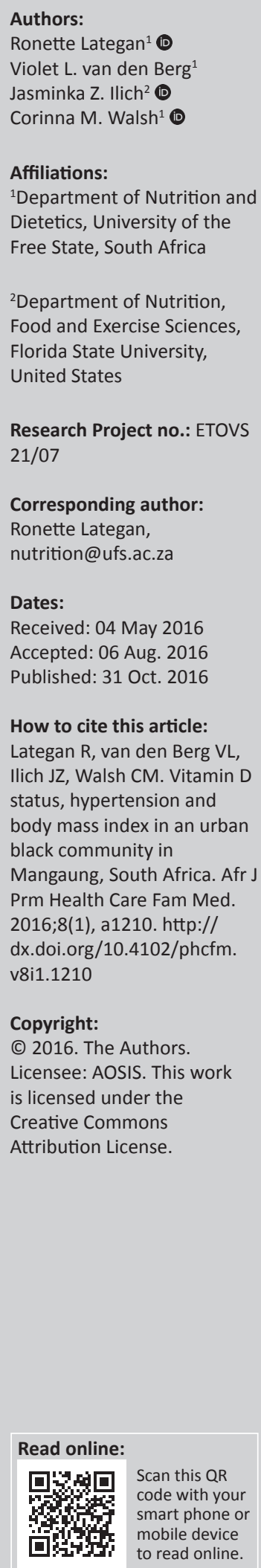

Background: A strong relationship exists between hypertension and body weight. Research has linked both higher blood pressure and body weight with lower vitamin D status.

Objective: This study assessed the vitamin D status of a low-income, urban, black community in South Africa, to examine whether serum levels of 25-hydroxy vitamin D [25(OH)D] are associated with hypertension and body mass index (BMI).

Methods: Data collected from 339 adults (25-64 years) from the Assuring Health for All in the Free State (AHA-FS) study were analysed. Variables measured include serum $25(\mathrm{OH}) \mathrm{D}$, blood pressure, weight and height to determine BMI, and HIV status.

Results: Mean 25(OH)D level was $38.4 \pm 11.2 \mathrm{ng} / \mathrm{mL}$ for the group; $43.5 \pm 11.8 \mathrm{ng} / \mathrm{mL}$ and $37.0 \pm 10.6 \mathrm{ng} / \mathrm{mL}$ for males and females, respectively. Approximately $40 \%$ of the participants were HIV-positive and $63.4 \%$ hypertensive. Based on BMI, $11.8 \%$ were underweight, $33.0 \%$ normal weight, $23.0 \%$ overweight and $32.1 \%$ obese. HIV status showed no correlation with 25(OH)D levels when controlling for BMI. Poor inverse relationships were found between BMI and 25(OH)D $(p=0.01)$, and between mean arterial blood pressure and $25(\mathrm{OH}) \mathrm{D}$ $(p=0.05)$. When controlling for BMI, no correlation was found between $25(\mathrm{OH}) \mathrm{D}$ and the prevalence of hypertension or mean arterial blood pressure.

Conclusion: Approximately $96 \%$ of participants had an adequate vitamin D status, which could be attributed to latitude, sunny conditions and expected high levels of sun exposure because of living conditions. Results confirmed a poor inverse relationship between vitamin D status and hypertension, which seems to be dependent on BMI.

\section{Introduction}

Hypertension and obesity are global health concerns that affect morbidity and mortality in many communities. A strong relationship exists between body weight and the prevalence of hypertension. The risk of developing hypertension is two to six times higher in overweight than normal weight individuals, and evidence from almost all clinical trials recommends weight loss as first-line treatment for lowering blood pressure. ${ }^{1,2,3}$ In recent years, vitamin D has become a nutrient of interest, with researchers investigating its role in various disease conditions. Although vitamin $\mathrm{D}$ status and its role in many non-skeletal health conditions have been investigated widely, its relationship with chronic conditions, including hypertension and obesity, still remains controversial, ${ }^{4}$ with only a few studies performed in black South Africans.

An inverse relationship, often age related, between vitamin D status and systolic blood pressure has been described and links lower serum 25-hydroxy vitamin D [25(OH)D] levels with a higher risk of hypertension. ${ }^{5,6,7,8}$ Vitamin D seems to act as a negative regulator of the renin gene, ${ }^{9}$ with a vitamin D deficiency promoting an increase in blood pressure by increasing the expression of renin. Renin activates angiotensin II, which increases blood pressure by direct vasoconstriction and by causing sodium and water retention in the kidney., $\mathrm{A}$ meta-analysis by the Endocrine Society Task Force, however, concluded that evidence of vitamin D improving cardiovascular risk factors is weak or non-existent. ${ }^{10} \mathrm{~A}$ review by Wang ${ }^{11}$ concluded that maintenance of an adequate vitamin D status is beneficial to cardiovascular and cerebrovascular health. However, as Vaidya and Forman ${ }^{5}$ cautioned in their review, supplementation with vitamin $\mathrm{D}$ in many studies has failed to lower blood pressure levels, and the relationship should be investigated further before vitamin $\mathrm{D}$ is recommended as a treatment option.

An inverse relationship between body mass index (BMI) and vitamin D status has been described. ${ }^{12,13,14}$ Wortsman et al. ${ }^{15}$ have shown that both obese and normal weight persons' skin 
produces the same amount of vitamin D under the same conditions, but that $57 \%$ less vitamin $\mathrm{D}$ is absorbed into the circulation of obese persons, because of the higher amount of subcutaneous fat that traps the cholecalciferol. Sun exposure in obese individuals with a low vitamin D status, therefore, does not seem to be the solution for normalising vitamin D status, and it should rather be supplemented orally so that it is released into circulation before being stored in the adipose tissue. $^{15}$

Although HIV infection may influence body weight, which in turn may have an effect on vitamin D levels, similar mean serum 25(OH)D levels have been reported in HIV-infected and non-infected individuals. ${ }^{16}$

The amount of time that skin needs to be exposed to sun in order to obtain adequate ultraviolet B (UVB) exposure for sufficient production of vitamin D3 in human skin depends on the solar elevation angle (time of day and latitude), as well as surface and atmospheric conditions. ${ }^{17}$ For a darker pigmented skin, the need for sun exposure to produce adequate vitamin $\mathrm{D}$ can be up to 40 times longer than what is needed by a fair skin because of the higher amount of cutaneous melanin in darker pigmented skin, which slows conversion to cholecalciferol (pre-vitamin D) in the skin. For a darker pigmented skin, estimated exposure times in central South Africa (latitude $29^{\circ} 10^{\prime} \mathrm{S}$ for Mangaung) vary between $136 \mathrm{~min}$ at 09:00 in the winter to $16 \mathrm{~min}$ at 12:00 in the summer, based on a quarter of body surface exposed (arms, hands and face). ${ }^{13,17}$

This article reports on the vitamin D status of a low-income, black, urban community in Mangaung, South Africa, and discusses the relation between vitamin $\mathrm{D}$ status and the prevalence of hypertension and BMI, taking into account possible confounding factors, such as HIV status. We hypothesised that $25(\mathrm{OH}) \mathrm{D}$ levels in this population will be inadequate because of low dietary intake and dark skin of participants, and that vitamin D status will be inversely correlated with blood pressure and BMI.

\section{Methods}

For this cross-sectional study, baseline data from the Assuring Health for All in the Free State (AHA-FS) study in an urban setting were used. Data were collected in autumn, over a period of 2 weeks from 6 urban township areas in Bloemfontein, South Africa. Households were selected by proportional cluster sampling, stratified by area and formal plot/squatter households in open areas. Using randomly selected $\mathrm{X}$ and $\mathrm{Y}$ coordinates, 100 starting points were selected. From each starting point, five adjacent households were invited to participate and written informed consent obtained from all eligible adults (25-64 years). Participants assembled at the central research centre after an overnight fast, where blood pressure and anthropometric measurements were obtained, and blood samples drawn to assess vitamin D and HIV status.
Blood pressure was measured by a registered medical practitioner according to recognised guidelines. ${ }^{18}$ Hypertension was defined as systolic blood pressure of $\geq 140 \mathrm{mmHg}$ and/or diastolic blood pressure $\geq 90 \mathrm{mmHg}$. ${ }^{2}$ Participants using prescription medication for the management of hypertension at the time of the consultation were also classified as hypertensive..$^{19}$ The mean arterial pressure was calculated as follows: diastolic blood pressure $+1 / 3$ (systolic blood pressure diastolic blood pressure). ${ }^{20}$

Anthropometric measurements were taken by trained finalyear dietetics students, under supervision of the researchers. Body weight was determined using WHO guidelines ${ }^{21}$ on a floor-type Seca 770 digital scale (Medical Scales and Measuring Systems, Seca kk., Japan) with accuracy to $100 \mathrm{~g}$ and a maximum capacity of $200 \mathrm{~kg}$. Height was measured with a Seca stadiometer (Medical Scales and Measuring Systems, Seca kk., Japan) accurate to the nearest $5 \mathrm{~mm} .{ }^{21}$ BMI $\left(\mathrm{kg} / \mathrm{m}^{2}\right)$ was calculated and interpreted according to WHO guidelines. ${ }^{22}$

HIV status was determined from fasting venous blood samples after counselling and informed consent was obtained. Primary screening for HIV was performed using the Enzygnost HIV Integral II Ag/Ab test (Dade Behring, Marburg, Germany). Results were confirmed by the Vironostika HIV Uni-Form II Ag/Ab test (bioMérieux, Marcy l'Etoile, France) and participants could indicate whether they wished to know their status. Incidence reported for HIV infection in South Africa varies and is estimated at more than $17 \%{ }^{23,24}$ Although HIV infection influences body weight, which is associated with vitamin D status (particularly in obese individuals), similar mean serum 25(OH)D levels have been reported in HIV-positive and -negative individuals. ${ }^{16}$

A chemiluminescent immunoassay, as determined by means of the Liaison 25(OH) Vitamin D Total Assay Kit (DiaSorin, Stillwater, MN, USA), was used to measure serum $25(\mathrm{OH}) \mathrm{D}$ levels. Although a serum level of lower than $30 \mathrm{ng} / \mathrm{mL}$ $25(\mathrm{OH}) \mathrm{D}$ was previously used to indicate a deficiency, ${ }^{25}$ the Health and Medicine Division of the National Academies of sciences, Engineering and Medicine recently lowered the cutoff value for adequate vitamin D status to $20 \mathrm{ng} / \mathrm{mL} .{ }^{26}$ For the purpose of this study, a serum $25(\mathrm{OH})$ D level of more than $20 \mathrm{ng} / \mathrm{mL}$ indicated an acceptable vitamin $\mathrm{D}$ status, while a value of $12-20 \mathrm{ng} / \mathrm{mL}$ indicated inadequacy, and a level lower than $12 \mathrm{ng} / \mathrm{mL}$ indicated deficiency. ${ }^{26}$

Analysis of data was performed with PASW (Predictive Analytics SoftWare) statistics software by SPSS (Version 18.0). Frequencies and percentages were used to express categorical data. Means and standard deviations, or percentiles, as appropriate, were used to express quantitative variables. Comparisons of means were performed using $t$-tests. Chisquare tests, two-tailed Pearson correlations and multivariate logistic regression models were used to describe and test associations between variables. A $p \leq 0.05$ was considered statistically significant. 


\section{Ethical considerations}

Ethical approval was obtained from the Ethics Committee of the Faculty of Health Sciences, University of the Free State (ETOVS: 21/07).

\section{Results}

In this study, 339 adults (76 males and 263 females) with complete data sets were included, with a mean age of 44.3 years, ranging between 25 and 64 years (Table 1). More than a third (39.8\%) of the sample was HIV-positive. In $41.6 \%$ of individuals, systolic blood pressure was $\geq 140 \mathrm{mmHg}$, while $46.6 \%$ had a diastolic blood pressure of $\geq 90 \mathrm{mmHg}$, indicating hypertension. Approximately one quarter (25.4\%) of participants used antihypertensive medication at the time of the study. Consequently, $63.4 \%$ (57.9\% of male and $65.0 \%$ of female participants) were classified as hypertensive.

The mean 25(OH)D level for the group was $38.4 \mathrm{ng} / \mathrm{mL}$ and was significantly higher in males than in females (43.5 and $37.0 \mathrm{ng} / \mathrm{mL}$, respectively; $p<0.001$ ).

A high incidence of overweight/obesity was found in this study population. Based on BMI, $11.8 \%$ of the study population was underweight $(25.0 \%$ of males and $8.0 \%$ of females), 33.0\% had a normal BMI, $23.0 \%$ was overweight and $32.1 \%$ obese. More than half $(55.1 \%)$ of the participants were either overweight or obese according to their BMI, with the majority of males $(81.6 \%)$ classified as underweight or normal weight and the majority of females (65.8\%) classified as overweight or obese.

The majority of the participants in this study had an acceptable vitamin D status, as indicated in Figure 1. Only one $(0.4 \%)$ female participant, which constituted $0.3 \%$ of the total population, had a deficient level of $25(\mathrm{OH}) \mathrm{D}$ $(<12 \mathrm{ng} / \mathrm{mL} ;<30 \mathrm{nmol} / \mathrm{L})$. Approximately $96 \%$ of the total group of participants had 25(OH)D levels of $>20 \mathrm{ng} / \mathrm{mL}$ (> $50 \mathrm{nmol} / \mathrm{L})$.
In Figure 2, participants' vitamin D status, classified as deficient, inadequate and acceptable, is indicated according to BMI category, showing a tendency of an increase in the prevalence of lower vitamin D status as BMI category increases. A Pearson's correlation showed an inverse relationship $(r=-0.303 ; p<0.001)$ between BMI and 25(OH) $\mathrm{D}$ levels as a measure of vitamin $\mathrm{D}$ status.

The large majority of participants (95.9\%) had an acceptable vitamin D status. No association between vitamin D status and the prevalence of hypertension was found. Of the hypertensive individuals, $95.8 \%$ had an acceptable vitamin D status, while $96.0 \%$ of the normotensive individuals had an acceptable vitamin D status.

A Pearson's correlation of mean arterial blood pressure and 25(OH)D levels showed a very weak inverse correlation $(r=-0.136 ; p=0.012)$. Given the influence of overweight/ obesity, as indicated by BMI, on both $25(\mathrm{OH}) \mathrm{D}$ levels and blood pressure, the association between $25(\mathrm{OH}) \mathrm{D}$ levels and mean arterial blood pressure was determined, controlling for BMI. No significant correlation between 25(OH)D levels and

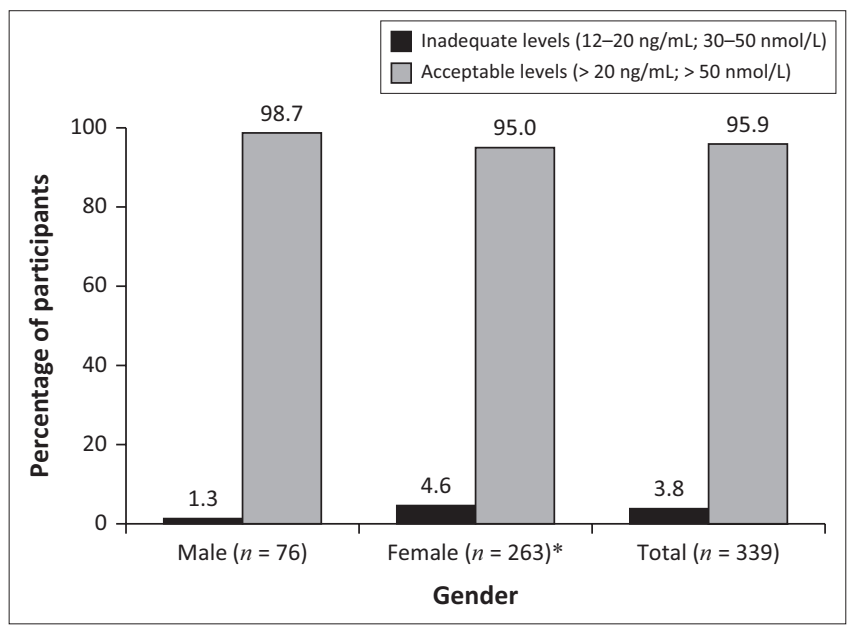

Source: Authors' own work

FIGURE 1: Vitamin D status of participants.

TABLE 1: General description of the study population in terms of age, blood pressure, body mass index (BMI) and 25-hydroxy vitamin D [25(OH)D] levels.

\begin{tabular}{|c|c|c|c|c|}
\hline Variable & $N$ & Mean \pm s.d. & Minimum & Maximum \\
\hline \multicolumn{5}{|c|}{ Anthropometric measurements } \\
\hline Age (years) & 339 & $44.3 \pm 10.6$ & 25.0 & 63.0 \\
\hline Height $(\mathrm{cm})$ & 339 & $159.4 \pm 7.8$ & 139.8 & 180.0 \\
\hline Weight (kg) & 339 & $70.1 \pm 21.4$ & 31.9 & 140.0 \\
\hline \multicolumn{5}{|l|}{ Blood pressure } \\
\hline Systolic (mmHg) & 339 & $135.5 \pm 23.7$ & 72.0 & 203.0 \\
\hline Diastolic (mmHg) & 339 & $89.8 \pm 17.6$ & 46 & 188 \\
\hline \multicolumn{5}{|l|}{$\mathrm{BMI}\left(\mathrm{kg} / \mathrm{m}^{2}\right)$} \\
\hline Male & 76 & $21.4 \pm 5.6$ & 14.5 & 49.9 \\
\hline Female & 263 & $29.6 \pm 8.7$ & 13.3 & 55.7 \\
\hline Total & 339 & $27.8 \pm 8.8$ & 13.3 & 55.7 \\
\hline \multicolumn{5}{|l|}{ 25(OH)D level (ng/mL) } \\
\hline Male & 76 & $43.5 \pm 11.8$ & 15.6 & 82.2 \\
\hline Female & 263 & $37.0 \pm 10.6$ & 8.7 & 64.8 \\
\hline Total & 339 & $38.4 \pm 11.2$ & 8.7 & 82.2 \\
\hline
\end{tabular}

Source: Authors' own work

s.d., standard deviation. 


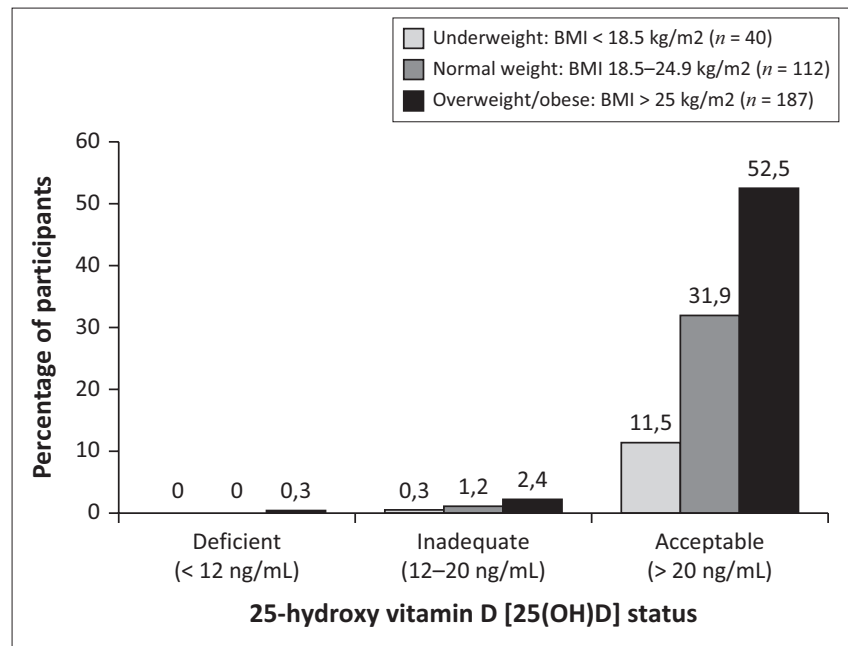

Source: Authors' own work

FIGURE 2: Vitamin D status in relation to body mass index (BMI) category.

hypertension $(r=-0.021 ; p=0.694)$ or mean arterial blood pressure levels $(r=-0.062 ; p=0.254)$ were found.

More than a third (39.8\%) of the study population was HIV-positive, although HIV status did not correlate significantly with $25(\mathrm{OH}) \mathrm{D}(r=0.101 ; p=0.06)$ when BMI was accounted for.

\section{Discussion}

In this study, a high prevalence of hypertension (63.4\%) and overweight/obesity (55.1\%) was found. Approximately $96 \%$ of participants had adequate vitamin D status (> $20 \mathrm{ng} / \mathrm{mL})$, which was not expected, because of the darker skin pigmentation of participants ${ }^{17}$ and expected low vitamin $\mathrm{D}$ intake because of the lower socio-economic area ${ }^{27}$ and absence of compulsory vitamin $\mathrm{D}$ fortification in the country.

The high incidence of HIV infection did not correlate with 25(OH)D levels, except through the indirect influence on weight and BMI. This finding was in agreement with Stephensen et al. ${ }^{16}$ who found no significant difference between the mean serum 25(OH)D levels of HIV-positive and HIV-negative individuals.

An inverse relationship between 25(OH)D levels and both BMI and mean arterial blood pressure was found. However, when controlled for BMI, no significant relationship was found between $25(\mathrm{OH}) \mathrm{D}$ and hypertension or mean arterial blood pressure, indicating that body weight may be a confounding factor in the relationship between vitamin D levels and hypertension.

When comparing this population, from a low socio-economic, disadvantaged background, ${ }^{27}$ with populations from developed countries where foods are also commonly fortified with vitamin $\mathrm{D}$, it was surprising that the mean serum $25(\mathrm{OH}) \mathrm{D}$ level of $38.4 \mathrm{ng} / \mathrm{mL}$ in this population was significantly higher $(p<0.001)$ than that reported from the
US National Health and Nutrition Examination Survey (males $25.2 \mathrm{ng} / \mathrm{mL}$; females $24.6 \mathrm{ng} / \mathrm{mL}$; black population $15.7 \mathrm{ng} / \mathrm{mL}){ }^{13}$ or that reported for participants from the Prostate Lung, Colorectal, and Ovarian Cancer Screening Trial cohort (males $24.4 \mathrm{ng} / \mathrm{mL}$; females $26.2 \mathrm{ng} / \mathrm{mL}$ ). ${ }^{12}$ As in other studies, higher mean $25(\mathrm{OH}) \mathrm{D}$ levels were found in males compared to females $(43.5 \mathrm{ng} / \mathrm{mL}$ versus $37.0 \mathrm{ng} / \mathrm{mL}){ }^{13,28}$

Similar to the high proportion of individuals with adequate vitamin D status found in this adult population, Poopedi et al. ${ }^{29}$ also reported that $74 \%$ of a population of South African children aged 10 years old, living in the urban area of Johannesburg, had adequate vitamin D status (using cut-off values of $\geq 75 \mathrm{nmol} / \mathrm{L}$ or $\geq 30 \mathrm{ng} / \mathrm{mL}$ ). The mean serum $25(\mathrm{OH}) \mathrm{D}$ levels for the black children in the study were $34.5 \mathrm{ng} / \mathrm{mL}$ for girls and $40.1 \mathrm{ng} / \mathrm{mL}$ for boys, ${ }^{29}$ which agrees with the higher levels found in the black adults in the current study.

In our study, a notably higher vitamin D status, compared to studies from other countries, was found. A much lower vitamin D status was expected because of the dark skin colour of the study population, low income levels ${ }^{27}$ translating to low intakes of vitamin D-rich foods, the fact that vitamin $\mathrm{D}$ fortification is not mandatory in South Africa, and the large incidence of overweight/obesity in this study group. The high levels of $25(\mathrm{OH}) \mathrm{D}$ may probably be ascribed to the favourable latitude ( $\left.29^{\circ} 10^{\prime} \mathrm{S}\right)$ of and general sunny weather experienced in Bloemfontein, South Africa; the fact that blood samples were taken during autumn, and the fact that living conditions and lifestyles of this community allow high levels of sun exposure, linked to outdoor living conditions.

\section{Acknowledgements}

The authors acknowledge financial support received from the South African National Research Foundation (NRF), grant number TTK2006050800013; the Department of Biostatistics, Faculty of Health Sciences, University of the Free State, for providing assistance with the analysis and interpretation of data. The Fulbright programme (USA) is acknowledged for assistance during writing of the report. Dr. Daleen Struwig, medical writer, Faculty of Health Sciences, UFS, is acknowledged for technical and editorial preparation of the manuscript.

\section{Competing interests}

The authors declare that they have no financial or personal relationships which may have inappropriately influenced them in writing this article.

\section{Authors' contributions}

R.L., V.L.vdB. and C.M.W. were responsible for project planning, design, data collection and analysis. J.Z.L. supported project design and data analysis. All authors contributed towards preparation of the manuscript. 


\section{References}

1. Steyn K. Hypertension in South Africa. In: Steyn K, Fourie J, Temple N, editors. Chronic diseases of lifestyle: 1995-2005. Technical report [homepage on the Internet]. Cape Town: South African Medical Research Council, 2006; p. 80-96 [cited 2016 May 4] Available from: www.mrc.ac.za/noncomm/cdl1995-2005.pdf

2. Raymond JL, Couch SC. Medical nutrition therapy for cardiovascular disease. In: Mahan KL, Escott-Stump S, Raymond JL, editors. Krause's food and the nutrition care process. 13th ed. Missouri: Elsevier Saunders, 2012; p. 742-781.

3. Appel LJ. ASH position paper: Dietary approaches to lower blood pressure. J Clin Hypertens. 2009;11(7):358-368. http://dx.doi.org/10.1111/j.1751-7176.2009. 00136.x

4. Post JL, llich JS. Controversies in vitamin D recommendations and its possible roles in nonskeletal health issues. J Nutr Food Sci [serial online]. 2013 [cited $2016 \mathrm{May}$ 4]:3:213. http://dx doi.org/10.4172/2155-9600.1000213. Available from: http:// 4];3:213. http://dx.doi.org/10.4172/2155-9600.1000213. Avallable from: http:// www.omicsonline.

5. Vaidya A, Forman JP. Vitamin D and hypertension: Current evidence and future directions. Hypertension. 2010;56(5):774-779. http://dx.doi.org/10.1161/ HYPERTENSIONAHA.109.140160

6. Judd SE, Nanes MS, Ziegler TR, Wilson PWF, Tangpricha V. Optimal vitamin D status attenuates the age-associated increase in systolic blood pressure in white Americans: Results from the third National Health and Nutrition Examination Survey. Am J Clin Nutr. 2008;87(1):136-141. PMID 18175747.

7. Forman JP, Giovannucci E, Holmes MD, et al. Plasma 25-hydroxyvitamin D levels and risk of incident hypertension. Hypertension. 2007;49(5):1063-1069. http:// dx.doi.org/10.1161/HYPERTENSIONAHA.107.087288

8. Li YC, Qiao G, Uskokovic M, Xiang W, Zheng W, Kong J. Vitamin D: A negative endocrine regulator of the rennin-angiotensin system and blood pressure. J Steroid Biochem Mol Biol. 2004;89-90(1-5):387-392. http://dx.doi.org/10. 1016/j.jsbmb.2004.03.004

9. Rammos G, Tseke P, Ziakka S. Vitamin D, the rennin-angiotensin system, and insulin resistance. Int Urol Nephrol. 2008;40(2):419-426. http://dx.doi.org/10. 1007/s11255-007-9244-4

10. Rosen CJ, Adams JS, Bikle DD, et al. The nonskeletal effects of vitamin D: An Endocrine Society scientific statement. Endocr Rev. 2012;33(3):456-492. http:// dx.doi.org/10.1210/er.2012-1000

11. Wang S. Epidemiology of vitamin D in health and disease. Nutr Res Rev. 2009;22(2):188-203. http://dx.doi.org/10.1017/S0954422409990151

12. Brock K, Huang WY, Fraser DR, et al. Low vitamin $D$ status is associated with physical inactivity, obesity and low vitamin D intake in a large US sample of healthy middleaged men and women. J Steroid Biochem Mol Biol. 2010;121(1-2):462-466. http://dx.doi.org/10.1016/j.jsbmb.2010.03.091

13. Reis JP, Michos ED, Von Mühlen D, Miller ER. Differences in vitamin D status as a possible contributor to the racial disparity in peripheral arterial disease. Am J Clin Nutr. 2008;88(6):1469-1477. http://dx.doi.org/10.3945/ajcn.2008.26447

14. Truesdell D, Shin H, Liu P-Y, llich JZ. Vitamin D status and Framingham Risk Score in overweight postmenopausal women. J Womens Health. 2011;20(9):1341-1348. http://dx.doi.org/10.1089/jwh.2010.2599
15. Wortsman J, Matsuoka LY, Chen TC, Lu Z, Holick MF. Decreased bioavailability of vitamin D in obesity. Am J Clin Nutr. 2000;72(3):690-693. PMID 10966885.

16. Stephensen CB, Marquis GS, Kruzich LA, Douglas SD, Aldrovandi GM, Wilson CM. Vitamin D status in adolescents and young adults with HIV infection. Am J Clin Nutr. 2006;83(5):1135-1141. PMID 16685057.

17. Webb AR, Engelsen $\mathrm{O}$. Calculated ultraviolet exposure levels for a healthy vitamin D status. Photochem Photobiol. 2006;82(6):1697-1703. http://dx.doi.org/10. 1111/j.1751-1097.2006.tb09833.x

18. National Institutes of Health, National Heart, Lung, and Blood Institute, Nationa High Blood Pressure Education Program (NIH). The seventh report of the Joint National Committee on prevention, detection, evaluation, and treatment of high blood pressure [homepage on the Internet]. [cited 2016 May 4]. Available from: http://www.nhlbi.nih.gov/guidelines/hypertension/jnc7full.pdf

19. Wallace C, Xue MZ, Caulfield M, Munroe PB. Genome scans in hypertension. In: Dominiczak AF, Connell JMC, editors. Handbook of hypertension, vol. 24. Genetics of hypertension. Edinburgh: Elsevier, 2007; p. 49-66.

20. Sanada H, Yatabe J, Midorikawa S, et al. Single-nucleotide polymorphisms for diagnosis of salt-sensitive hypertension. Clin Chem. 2006;52(3):352-360. http:// dx.doi.org/10.1373/clinchem.2005.059139

21. World Health Organization (WHO). WHO STEPS surveillance: Guide to physical measurements [homepage on the internet]. [cited 2016 May 4]. Available from: http://www.who.int/chp/steps/part3_section3.pdf

22. World Health Organization (WHO). Global database on body mass index [homepage on the internet]. [cited 2016 May 4]. Available from: http://apps.who. int/bmi/index.jsp?introPage=intro_3.html

23. Joint United Nations Programme on HIV/AIDS (UNICEF). Global report: UNAIDS report on the global AIDS epidemic 2010 [homepage on the internet]. [cited 2016 May 4]. Available from: www.unaids.org/globalreport/.../20101123_Global Report_full_en.pdf

24. Groenewald AJ, Van Wyk HJ, Van Zyl S, Van der Merwe LJ, Walsh CM. Staging and haematological abnormalities of HIV-infected persons in the rural Free State Province of South Africa. Afr J Prim Health Care Fam Med. 2011;3(1):Art. \#222, 4 pages. http://dx.doi.org/10.4102/phcfm.v3i1.222

25. Gallagher ML. The nutrients and their metabolism. In: Mahan KL, Escott-Stump S editors. Krause's food and nutrition therapy. 12th ed. Philadelphia, PA: WB Saunders Company; 2008, p. 39-143.

26. Health and Medicine Division. The National Academies of Science, Engineering and Medicine. Dietary reference intakes for calcium and vitamin D [homepage on the Internet]. [cited 2016 May 4]. Available from: http://www.nationalacademies. $\mathrm{org} / \mathrm{hmd} /$ Reports/2010/Dietary-Reference-Intakes-for-Calcium-and-Vitamin-D/ Report-Brief.aspx

27. Walsh CM, Van Rooyen FC. Household food security and hunger in rural and urban communities in the Free State Province, South Africa. Ecol Food Nutr. 2015;54(2):118-137. http://dx.doi.org/10.1080/03670244.2014.964230

28. Lips P. Worldwide status of vitamin D nutrition. J Steroid Biochem Mol Biol. 2010;121(1-2):297-300. http://dx.doi.org/10.1016/j.jsbmb.2010.02.021

29. Poopedi MA, Norris SA, Pettifor JM. Factors influencing the vitamin D status of 10-year-old urban South African children. Public Health Nutr. 2011;14(2):334-339. http://dx.doi.org/10.1017/S136898001000234X 